\title{
Reevaluation of RAPD markers involved in a case of stingray misidentification (Dasyatidae: Dasyatis)
}

\author{
V.V. Faria' ${ }^{1}$ L.S. Rolim ${ }^{1,2}$, L.A.L. Vaz $^{3}$ and M.A.A. Furtado-Neto ${ }^{1,2}$ \\ 'Instituto de Ciências do Mar - LABOMAR, \\ Universidade Federal do Ceará, Fortaleza, CE, Brasil \\ ${ }^{2}$ Departamento de Engenharia de Pesca, Centro de Ciências Agrárias, \\ Universidade Federal do Ceará, Fortaleza, CE, Brasil \\ ${ }^{3}$ Haugesund, Rogaland, Norway \\ Corresponding author: V.V. Faria \\ E-mail: vicentefaria@gmail.com
}

Genet. Mol. Res. 11 (4): 3835-3845 (2012)

Received April 4, 2012

Accepted June 22, 2012

Published October 25, 2012

DOI http://dx.doi.org/10.4238/2012.October.25.2

\begin{abstract}
We investigated a reported case of stingray Dasyatis americana misidentification not detected in a published study using the random amplified polymorphic DNA (RAPD) technique. If the referred specimen (landed by fisheries in Ceará, northeastern Brazil) was misidentified (as Dasyatis centroura) in the field, why did its RAPD data fail to clarify the mistake? Was it due to limitations of RAPD markers or perhaps to a taxonomic issue? Contrary to our initial expectations, neither of these hindered the detection of the misidentification. After reanalyzing the primary genetic data associated with the misidentified specimen (PCR gel photographs and/or matrices of presence/absence of markers for six RAPD primers), we found that the RAPD markers were sufficient to correctly assign the misidentified specimen to its proper species identity. In the original study, the specimen misidentification
\end{abstract}


was neither noticed by the authors nor apparent in the published article due to how their results were interpreted and presented.

Key words: Dasyatis americana; Dasyatis centroura; Fishery product identification

\section{INTRODUCTION}

Fishery products frequently have body parts removed, preventing species identification based on morphological characters. In other cases, even when intact specimens are brought to shore or port, the often chaotic environment of a fishery landing is not conducive to time-consuming identification methods. Incomplete or incorrect identifications of captured species undermine an essential aspect of fishery management (Morgan and Burgess, 2005). Several techniques using molecular markers have been used to overcome these problems and help with species identification (Kochzius, 2009). Generally, these techniques involve tissue sampling of specimens/fishery products and subsequent laboratory work. Currently, some of the most used techniques are DNA barcoding (Holmes et al., 2009; Santander-Neto et al., 2011; but see Toffoli et al., 2008), polymerase chain reaction (PCR)-restriction fragment length polymorphism (Mendonça et al., 2009), and multiplex PCR (Mendonça et al., 2010). In addition to these recent techniques, several older molecular marker techniques have been used in fisheries (Carvalho and Pitcher, 1995). One of these is the random amplified polymorphic DNA (RAPD) technique.

RAPD markers have the advantages of not requiring previous knowledge of a species genome, generating large DNA polymorphism data, and being relatively inexpensive (Grosberg et al., 1996; Klinbunga et al., 2010; Yazbeck et al., 2011). These properties make the technique useful for the rapid screening of large numbers of specimens landed by fisheries. However, RAPD markers have some limitations. For example, interpreting banding patterns on a gel can be subjective because the intensity of the various markers may differ (Grosberg et al., 1996). Indeed, a study by Vaz et al. (2006) that used RAPD markers to explore the genetics of stingrays caught and landed by fisheries in Ceará State, Brazil, has been questioned. JucáQueiroz et al. (2008) have stated that one southern stingray, Dasyatis americana, was misidentified by Vaz et al. (2006) as the roughtail stingray D. centroura (Figure 1). This mistake raises several questions: If the specimen was misidentified in the field, why did its RAPD data fail to clarify the mistake? Are the limitations of the RAPD technique to blame? Alternatively, could a taxonomic issue be involved in this misidentification? Stingray taxonomy is not trivial, and three new Dasyatis species have been described in Brazilian coastal waters since 2000: $D$. marianae (Gomes et al., 2000; Rosa et al., 2000), D. colarensis (Santos et al., 2004), and D. hipostigma (Santos and Carvalho, 2004).

Sharks and rays are an important fishery product for Ceará State, the latter being largely used in traditional regional dishes (Furtado-Neto and Barros-Júnior, 2006). Among the local species, the stingrays $D$. americana and D. guttata are of greatest importance owing to their abundance in coastal fisheries (Silva et al., 2007). However, elasmobranchs (the group containing sharks and rays) are, in general, highly vulnerable to fishery overexploitation (Dulvy and Reynolds, 2009; Simpfendorfer and Kyne, 2009). Therefore, proper identification of stingray species involved in this trade is warranted. For this reason, if the species misiden- 
tification was undetected by Vaz et al. (2006) owing to limitations of RAPD markers, future studies of stingray identification using these markers should be avoided. However, if the misidentification was due to a taxonomic issue, an undetected species may have been exploited by fisheries without notice. In this study, we reanalyzed the primary RAPD data used by Vaz et al. (2006) to investigate the nature of the species misidentification and its lack of detection.

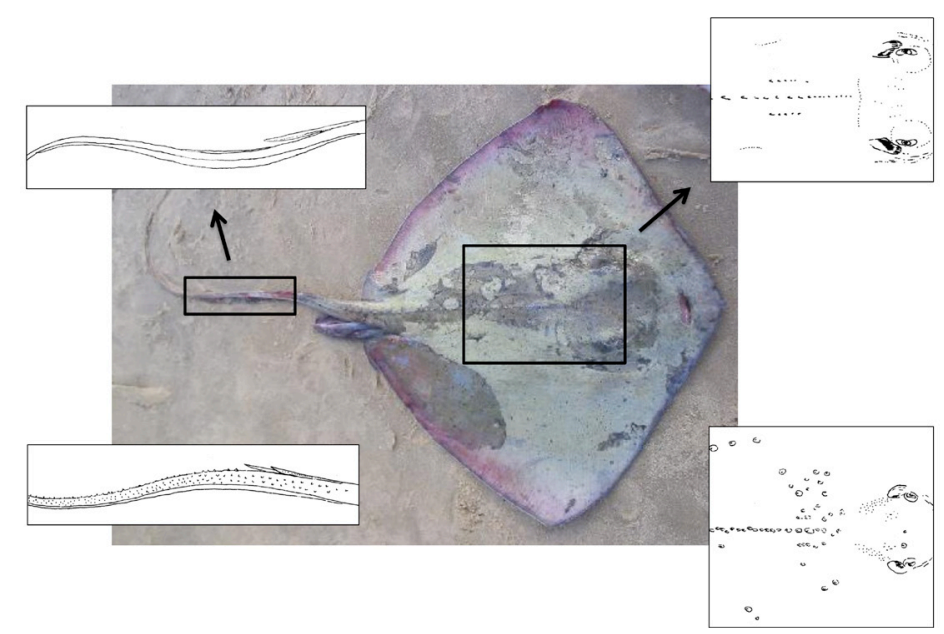

Figure 1. Southern stingray (Dasyatis americana) specimen from which random amplified polymorphic DNA (RAPD) markers were obtained by Vaz et al. (2006). This male specimen landed in Fortaleza, Ceará, Brazil, was originally misidentified as the roughtail stingray $D$. centroura. Black squares highlight morphologic characters that are diagnostic for the two species. 1) The breadth of the lower tailfold in D. americana is relatively greater than that in D. centroura (upper and lower left drawings, respectively). 2) D. americana has a row of tubercles on the midline of the back with two lines of small tubercles on each shoulder, whereas $D$. centroura has widely spaced mid-dorsal bucklers (upper and lower right drawings, respectively). [Redrawn from Bigelow and Schroeder (1953)].

\section{MATERIAL AND METHODS}

\section{RAPD markers}

Vaz et al. (2006) obtained RAPD-PCR data from tissue samples of 12 specimens landed by local artisanal fishermen in Fortaleza, Brazil. These specimens included Rhinobatos percellens $(\mathrm{N}=1), D$. americana $(\mathrm{N}=4), D$. guttata $(\mathrm{N}=2)$, and $D$. marianae $(\mathrm{N}=4)$. A fifth D. americana specimen was misidentified as D. centroura (Jucá-Queiroz et al., 2008), which is referred as Dasyatis sp or "D. centroura" throughout the present study. Vaz et al. (2006) performed PCR using six RAPD primers (Table 1). In the present study, PCR gel photographs from five of the six RAPD primers used by Vaz et al. (2006) were reexamined to construct new marker matrices. OPK 08 was omitted because no PCR gel photographs remained.

\section{Present study matrices}

Each PCR gel photograph was manually scored for the presence/absence of markers (bands), which resulted in five individual RAPD primer-specific matrices. An all-primers-com- 
bined data matrix was also assembled (total number of characters $=166$ ). These matrices are referred to herein as the present-study matrices. These six matrices were subjected to maximum parsimony (MP) analyses using PAUP* 4.02b (Swofford, 2000). Support for each node from the majority consensus tree from each dataset was investigated with 10,000 bootstrap pseudoreplicates. In addition, the all-primers-combined data matrix was also subjected to genetic distance analyses [neighbor joining (NJ), uncorrected P] using PAUP* 4.02b. To generate genetic distances for $\mathrm{NJ}$ analysis, we converted the presence/absence of band data to purine/pyrimidine nucleotide data ( 1 and 0 to $\mathrm{C}$ and $\mathrm{A}$, respectively) using MacClade 4.05 (Maddison and Maddison, 2005).

Table 1. Description of six primers used by Vaz et al. (2006) for amplification of RAPD markers from stingrays Dasyatis and guitarfish Rhinobatos landed by fisheries in Ceará State, Brazil.

\begin{tabular}{ll}
\hline Primer name & Sequence $\left(5^{\prime}-3^{\prime}\right)$ \\
\hline OPC 20 & ACTTCGCCAC \\
OPE 01 & CCCAAGGTCC \\
OPK 08 & GAACACTGGG \\
OPK 11 & AATGCCCCAG \\
OPJ 08 & CATACCGTGG \\
OPM 01 & GTTGGTGGCT \\
\hline
\end{tabular}

Primer sequences according to Operon Technologies Inc. The primers were chosen after initial testing of 20 primers. PCR were carried out by Vaz et al. (2006) in $25 \mu \mathrm{L}$ volumes as follows: $3 \mathrm{mM} \mathrm{MgCl}_{2}, 200 \mu \mathrm{M}$ dNTPs (GE HealthCare), 10 $\mathrm{pM} / \mu \mathrm{L}$ of one primer, 1.0 U DNA Taq Polymerase (Phoneutria), $20 \mathrm{ng}$ genomic DNA template, completed with ultrapure distilled water. Cycling conditions for all primers consisted of 3 cycles of $94^{\circ} \mathrm{C}$ for $60 \mathrm{~s}, 35^{\circ} \mathrm{C}$ for $60 \mathrm{~s}, 72^{\circ} \mathrm{C}$ for 120 s, followed by 37 cycles of $94^{\circ} \mathrm{C}$ for $10 \mathrm{~s}, 40^{\circ} \mathrm{C}$ for $30 \mathrm{~s}$, and $72^{\circ} \mathrm{C}$ for $120 \mathrm{~s}$, with a final extension at $72^{\circ} \mathrm{C}$ for 5 min.

\section{Vaz et al. (2006) matrices}

For comparative purposes, the same data handling and analyses described above were carried out for all six of the original individual RAPD primer matrices generated and used by Vaz et al. (2006). Because the OPK 08 matrix was available, this primer was included in the all-primers-combined data matrix for Vaz et al. (2006) (total number of characters $=182$ ). These matrices are referred to herein as the Vaz-2006 matrices.

\section{RESULTS}

\section{Analyses of present-study matrices}

MP analyses performed on the present-study all-primers-combined data matrix produced a single $D$. americana/Dasyatis sp clade (Figure 2). The same topology was obtained in MP analyses of three of five individual primers. In the two remaining primers, Dasyatis sp was either sister to D. americana or no D. americana/Dasyatis sp clade was recovered (Table 2).

$\mathrm{NJ}$ analysis carried out on the present-study all-primers-combined data matrix also produced a single $D$. americana/Dasyatis sp clade (Figure 3). Genetic distance (uncorrected P) between Dasyatis sp and any of the other four D. americana individuals ranged from 0.144 to 0.181 . In contrast, the genetic distances ranged from 0.398 to 0.440 between $D$. americana and $D$. guttata, from 0.392 to 0.482 between $D$. americana and D. marianae, and from 0.416 to 0.458 between $D$. guttata and D. marianae. 


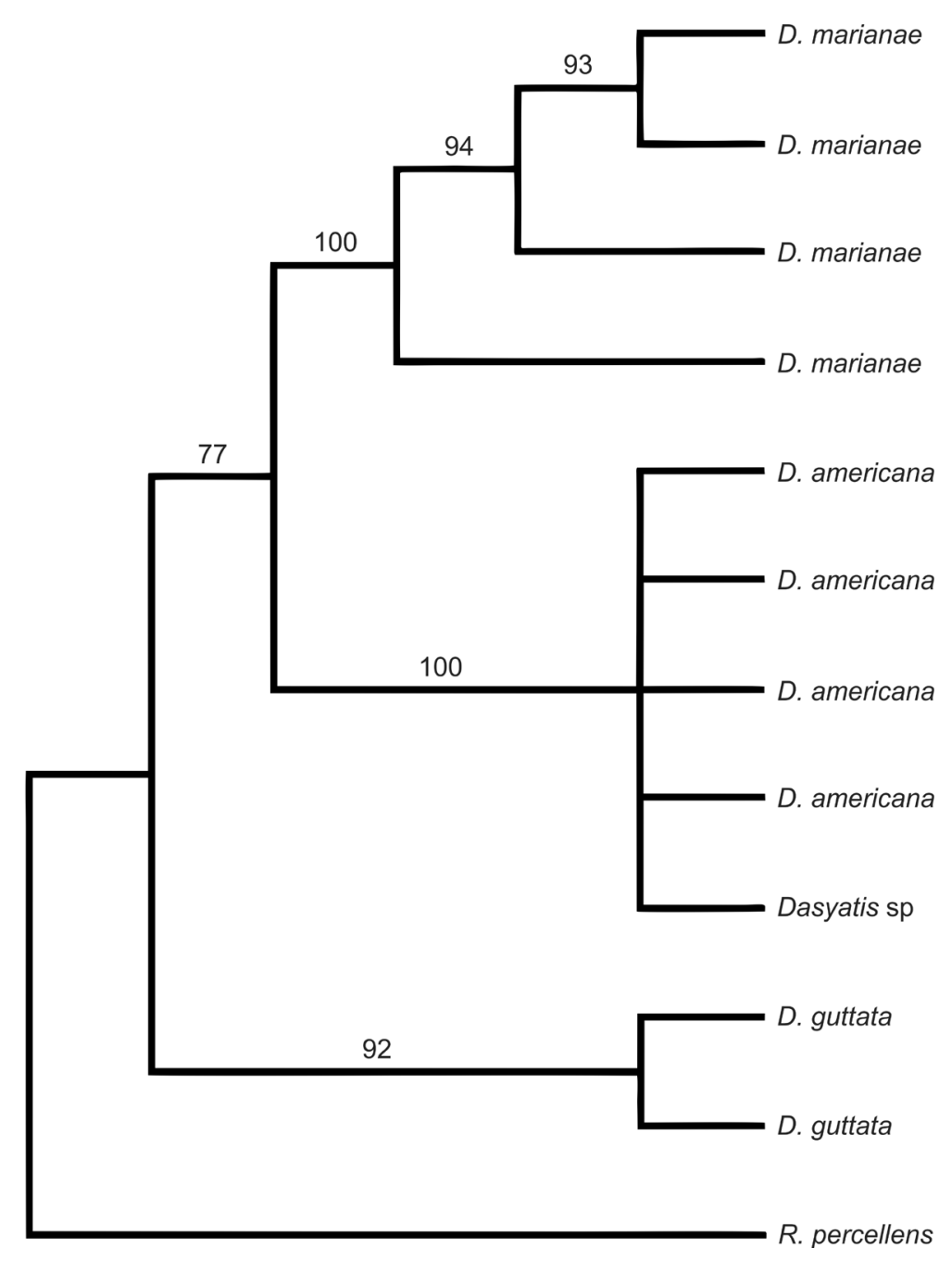

Figure 2. Maximum parsimony tree for the all-primers-combined dataset based on present-study matrices (RAPD primers: OPC 20, OPE 01, OPJ 08, OPK 11, and OPM 01): consensus tree of 10,000 bootstrap pseudoreplicates. Ingroup: stingray Dasyatis species. Outgroup: guitarfish Rhinobatos percellens.

Table 2. Phylogenetic relationships between four Dasyatis americana specimens and one Dasyatis sp specimen, per RAPD primer, after maximum parsimony analysis with 10,000 bootstrap pseudoreplicates based on present-study and Vaz-2006 matrices.

\begin{tabular}{lll}
\hline Clade & present-study & Vaz-2006 \\
\hline Dasyatis sp and D. americana & OPC 20, OPJ 08, OPE 01, & OPC 20, OPJ 08, OPE 01, OPK 11, OPK 08, \\
& All-primers-combined & All-primers-combined \\
Dasyatis sp sister to remaining D. americana & OPM 01 & OPM 01 \\
No clade & OPK 11 & - \\
\hline
\end{tabular}




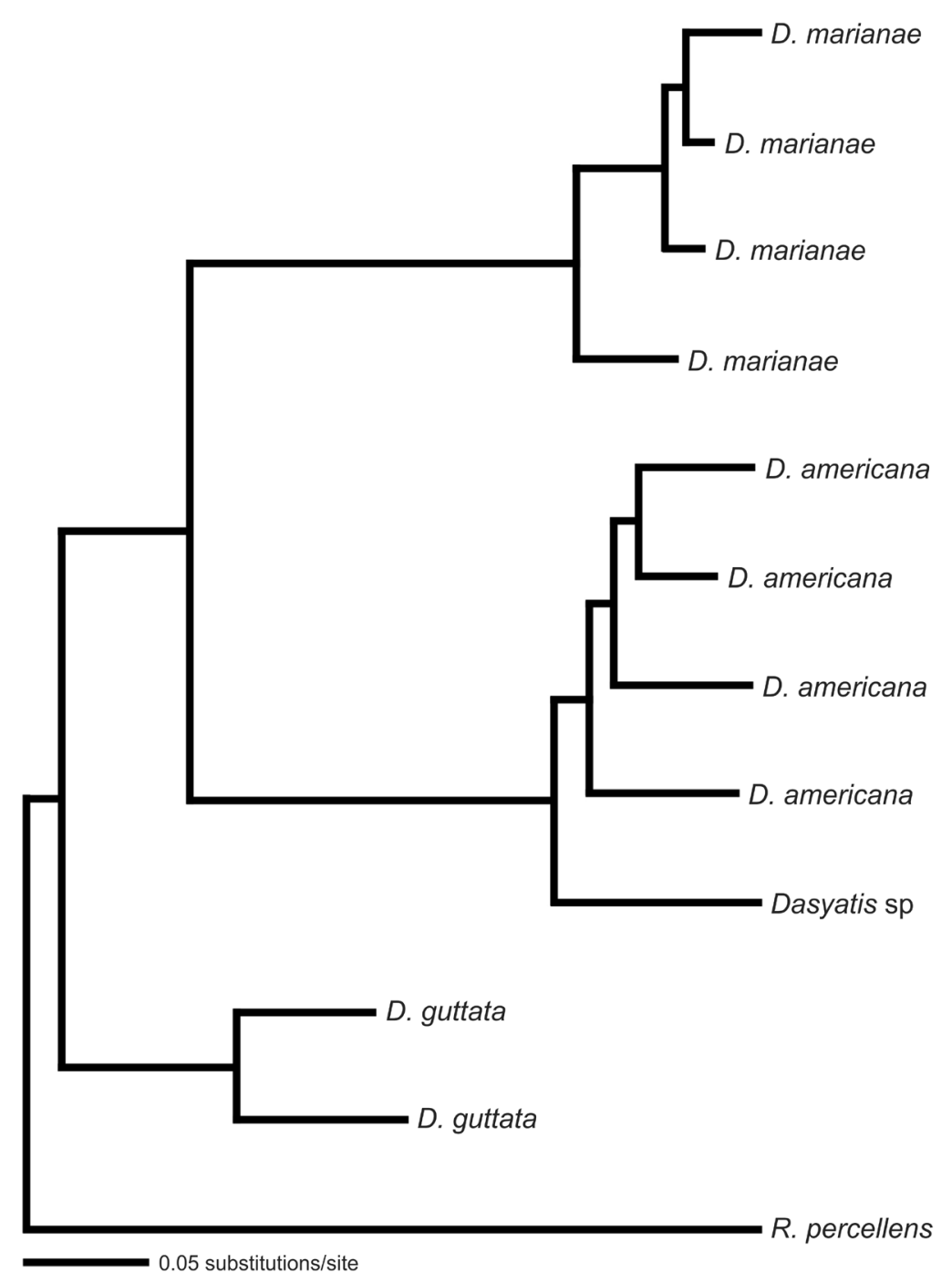

Figure 3. Neighbor joining tree for the all-primers-combined dataset based on present-study matrices (RAPD primers: OPC 20, OPE 01, OPJ 08, OPK 11, and OPM 01). Ingroup: stingray Dasyatis species. Outgroup: guitarfish Rhinobatos percellens.

\section{Analyses of Vaz-2006 matrices}

MP analyses based on Vaz-2006 matrices also most often showed Dasyatis sp and $D$. americana specimens as composing a single clade (Figure 4; Table 2). In fact, the phylogenetic signal of Vaz-2006 matrices was even stronger than that of the present-study matrices. For instance, analysis of the Vaz-2006 OPK 11 data matrix grouped D. americana and Dasyatis sp as a single clade, whereas that of the present-study OPK 11 matrix failed to do so (see Table 2). 


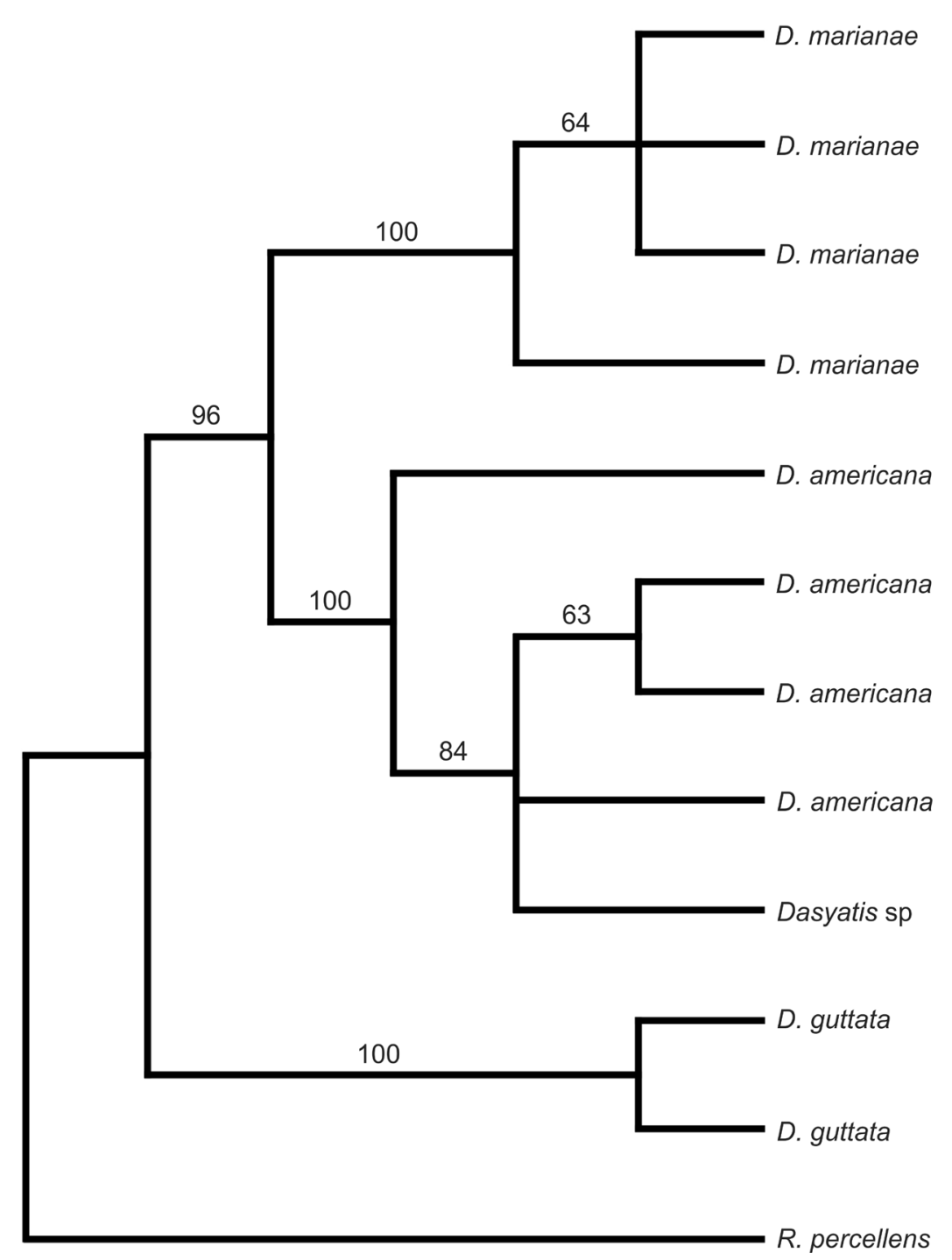

Figure 4. Maximum parsimony tree for the all-primers-combined dataset based on Vaz-2006 matrices (RAPD primers: OPC 20, OPE 01, OPJ 08, OPK 08, OPK 11, and OPM 01): consensus tree of 10,000 bootstrap pseudoreplicates. Ingroup: stingray Dasyatis species. Outgroup: guitarfish Rhinobatos percellens.

The NJ tree based on Vaz-2006 matrices also placed Dasyatis sp and D. americana in a single clade (Figure 5). The genetic distance (uncorrected P) between Dasyatis sp and any of the other four D. americana individuals ranged from 0.055 to 0.066 . In contrast, the genetic distances ranged from 0.396 to 0.445 between $D$. americana and $D$. guttata, from 0.319 to 0.341 between D. americana and D. marianae, and from 0.357 to 0.385 between $D$. guttata and D. marianae. 


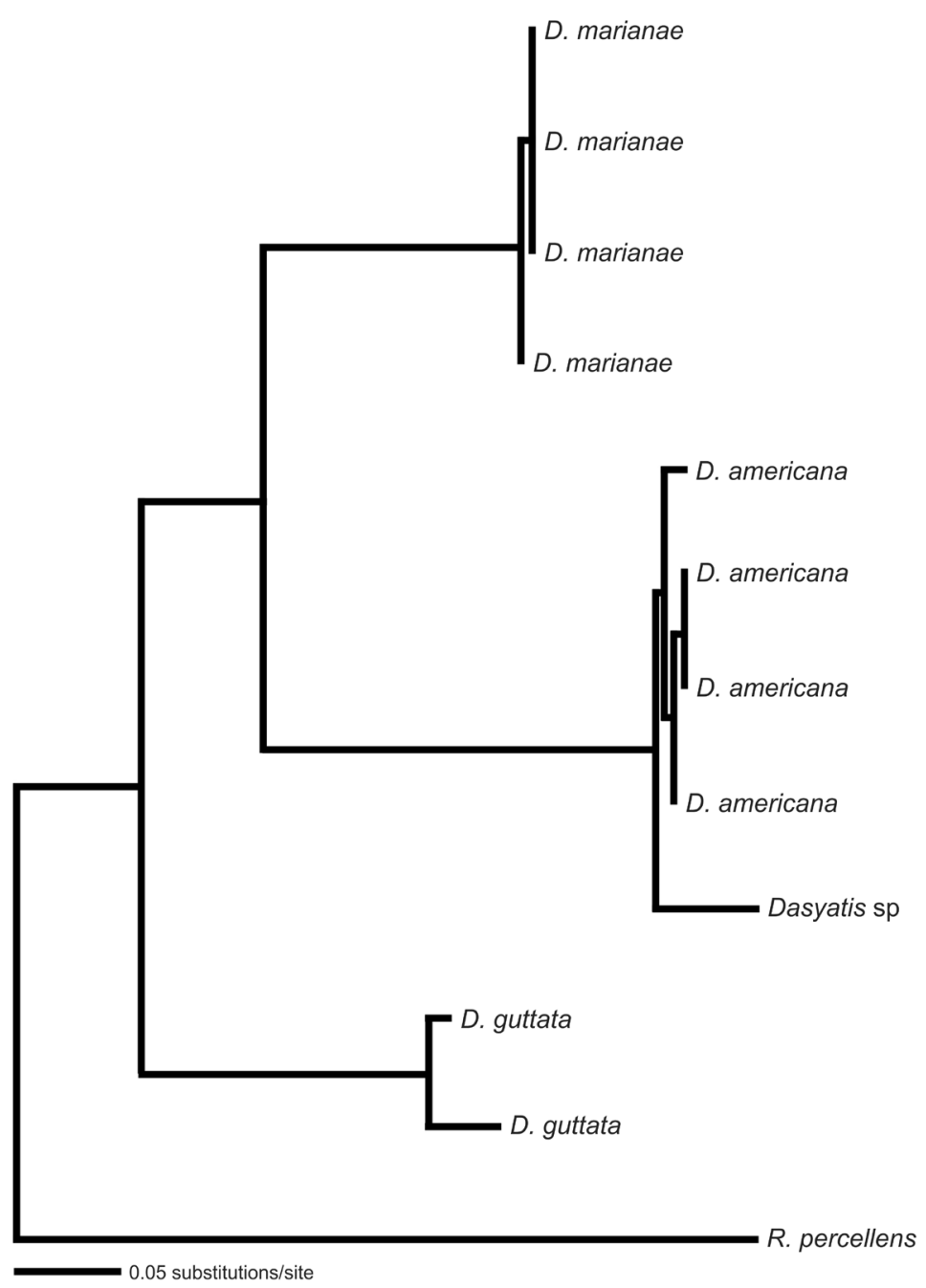

Figure 5. Neighbor joining tree for the all-primers-combined dataset based on Vaz-2006 matrices (RAPD primers: OPC 20, OPE 01, OPJ 08, OPK 08, OPK 11, and OPM 01). Ingroup: stingray Dasyatis species. Outgroup: guitarfish Rhinobatos percellens.

\section{DISCUSSION}

Contrary to our initial expectations, neither the limitations of the RAPD markers nor a taxonomic issue hindered the detection of the misidentification of the $D$. americana specimen, which was first noted by Jucá-Queiroz et al. (2008) based on external morphology evidence. Both MP and NJ analyses clearly indicated the identity of the Dasyatis sp specimen as D. americana. Two lines of evidence support this interpretation of the data. First, in nearly all MP and NJ analyses, Dasyatis sp and the remaining D. americana 
formed a single clade. Second, the genetic distance between the Dasyatis sp specimen and the remaining $D$. americana $(\sim 6 \%$ in the Vaz-2006 and $\sim 16 \%$ in the present-study matrices) was too small compared with the inter-species distances observed ( $37 \%$ in the Vaz2006 and $\sim 43 \%$ in the present-study matrices). Based on Frankham et al. (2004), the fact that the genetic distance between Dasyatis sp and D. americana is so much smaller than that between other well-recognized Dasyatis species can be interpreted as a suggestion that they belong to a single species.

At least two factors suggest that the results obtained in the present study are reliable. First, the data were subjected to two kinds of phylogenetic analyses. Fundamentally, in MP, the data are treated as discrete characters, whereas in distance methods, the data are used to construct a pairwise distance matrix, which in turn is used to build a phylogenetic tree (Page and Holmes, 1998). Therefore, the fact that the same topology was obtained after these two methods were applied suggests that the phylogenetic signal of the data is robust. Second, two researchers independently scored the presence/absence of bands in PCR gel photographs (Vaz LAL, in Vaz et al., 2006, and Rolim LS, in the present study). As previously mentioned, one of the limitations of RAPD markers is subjectivity in scoring ambiguous markers (Grosberg et al., 1996). Therefore, the overall congruence of the results further supports the robustness of the RAPD marker data examined.

As mentioned in the introduction, DNA barcoding is currently one prominent approach to the molecular identification of specimens (Holmes et al., 2009; Santander-Neto et al., 2011). Basically, this approach involves DNA extraction, PCR amplification using specific primers, and DNA sequencing. In contrast, RAPD techniques involve only DNA extraction and PCR using non-specific primers that can be used for amplification in any organism. These properties make RAPD techniques considerably more cost-effective, especially for organisms in which primers/markers that are more specific have not been developed or described (Klinbunga et al., 2010; Yazbeck et al., 2011). In this context, despite the widely known limitations of the RAPD technique (Grosberg et al., 1996), the markers investigated showed potential for use in Dasyatis stingray identification.

Given that the re-analyses of Vaz et al. (2006) RAPD data revealed that the specimen originally misidentified as " $D$. centroura" was in fact $D$. americana, why the authors of the referred study did not detect it? The oversight was due to an incorrect interpretation of results. The authors did not suspect that the close proximity of " $D$. centroura" and $D$. americana, seen also in their preliminary analyses, was evidence of a misidentification (Vaz L, personal account). Subsequently, because Vaz et al. (2006) intended only to determine the phylogenetic relationships among $D$. americana, " $D$. centroura", $D$. guttata, and $D$. marianae; they did not present an original MP tree that included all specimens analyzed. Instead, for clarity and simplicity, they drew a rectangular cladogram displaying only each of the four species investigated and the outgroup species (Figure 6). Although the phylogenetic relationships among the species were indeed presented in a clear and straightforward way through this presentation, with one specimen per species, the formation of a single clade including " $D$. centroura" and the remaining $D$. americana was unapparent. In addition, because branch lengths were not informative in the Vaz et al. (2006) tree, the samespecies scale of genetic distance between " $D$. centroura" and the remaining $D$. americana was no longer apparent. Consequently, the genetic evidence for the misidentification of the specimen was lost. 


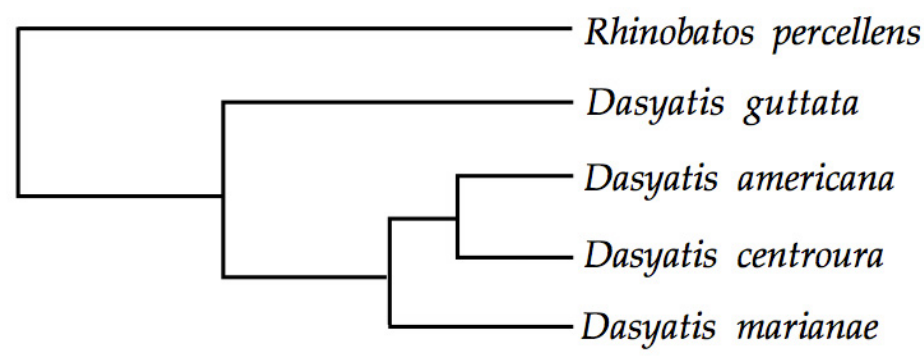

Figure 6. Rectangular cladogram drawn by Vaz et al. (2006) to represent the phylogenetic relationships among the stingrays Dasyatis americana, "D. centroura" (a misidentified D. americana), D. guttata, and D. marianae.

\section{ACKNOWLEDGMENTS}

We thank Tito M.C. Lotufo, Rodrigo Maggioni, and an anonymous reviewer for insightful comments on the manuscript; Aspen Padilla for language review; and José Renato O. César for suggestions on an earlier version of the manuscript. Fundação Cearense de Apoio ao Desenvolvimento Científico e Tecnológico - FUNCAP (Ceará State Research Council) provided a research fellowship to V.V. Faria. Coordenação de Aperfeiçoamento de Pessoal de Nível Superior - CAPES (Brazilian Ministry of Education) provided a Postdoctoral fellowship to V.V. Faria (Programa Nacional de Pós-Doutorado - PNPD). Conselho Nacional de Pesquisa e Desenvolvimento - CNPq (Brazilian National Research Council) provided a research productivity fellowship to M.A.A. Furtado-Neto.

\section{REFERENCES}

Bigelow HB and Schroeder WC (1953). Sawfishes, Guitarfishes, Skates and Rays. In: Fishes of the Western North Atlantic. Part 2 (Tee-Van J, Breder CM, Parr AE, Schroeder WC, et al., eds.). Sears Foundation for Marine Research, New Haven, 588.

Carvalho GR and Pitcher TJ (1995). Molecular Genetics in Fisheries. Chapman and Hall, London and New York.

Dulvy NK and Reynolds JD (2009). Biodiversity: skates on thin ice. Nature 462: 417.

Frankham R, Ballou JD and Briscoe DA (2004). A primer of Conservation Genetics. Cambridge University Press, Cambridge.

Furtado-Neto MAA and Barros-Júnior FVP (2006). Análise da produção pesqueira de elasmobrânquios no Estado do Ceará, Brasil, de 1991 a 2003. Arq. Ciên. Mar 39: 110-116.

Gomes UL, Rosa RS, Gadig OBF and McEachran JD (2000). Dasyatis macrophtalma sp. n.: a new species of stingray (Chondrichthyes, Dasyatidae) from the Southwestern Atlantic. Copeia 2000: 510-515.

Grosberg RK, Levitan DR and Cameron BB (1996). Characterization of Genetic Structure and Genealogies Using RAPDPCR Markers: A Random Primer for the Novice and Nervous. In: Molecular Zoology - Advances, Strategies, and Protocols (Ferraris JD and Palumbi SR, eds.). Wiley-Liss, Inc., New York, 65-100.

Holmes BH, Steinke D and Ward RD (2009). Identification of shark and ray fins using DNA barcoding. Fish. Res. 95: 280-288.

Jucá-Queiroz B, Santander-Neto J, Medeiros RS, Nascimento FCP, et al. (2008). Cartilaginous fishes (Class Chondrichthyes) of Ceará State, Brazil, Western Equatorial Atlantic - An update. Arq. Ciên. Mar 41: 73-81.

Klinbunga S, Yuvanatemiya V, Wongphayak S, Khetpu K, et al. (2010). Genetic population differentiation of the blue swimming crab Portunus pelagicus (Portunidae) in Thai waters revealed by RAPD analysis. Genet. Mol. Res. 9: 1615-1624.

Kochzius M (2009). Trends in Fishery Genetics. In: The Future of Fisheries Science in North America (Beamish RJ and Rothschild BJ, eds.). Fish \& Fisheries Series 31, Springer Netherlands, Dordrecht, 453-493. 
Maddison DR and Maddison WP (2005). MacClade 4: Analysis of Phylogeny and Character Evolution. Version 4.08a. Sinauer Associates, Sunderland.

Mendonça FF, Hashimoto DT, Porto-Foresti F, Oliveira C, et al. (2009). Identification of the shark species Rhizoprionodon lalandii and R. porosus (Elasmobranchii, Carcharhinidae) by multiplex PCR and PCR-RFLP techniques. Mol. Ecol. Resour. 9: 771-773.

Mendonça FF, Hashimoto DT, De-Franco B, Porto-Foresti F, et al. (2010). Genetic identification of lamniform and carcharhiniform sharks using multiplex-PCR. Conserv. Genet. Resour. 2: 31-35.

Morgan AC and Burgess GH (2005). Fishery-Dependent Sampling: Total Catch, Effort and Catch Composition. In: Management Techniques for Elasmobranch Fisheries (Musick J and Bonfil R, eds.). FAO Fisheries Technical Papers 474, Food and Agriculture Organization of the United Nations, Rome, 182-200.

Page RDM and Holmes EC (1998). Molecular Evolution: A Phylogenetic Approach. Blackwell Science, Oxford.

Rosa RS, Gadig OBF and Gomes UL (2000). Dasyatis marianae: The correct name for a recently described stingray (Chondrichthyes: Dasyatidae) from the Southwestern Atlantic. Copeia 2000: 889-890.

Santander-Neto J, Faria VV, Castro ALF and Burgess GH (2011). New record of the rare ragged-tooth shark, Odontaspis ferox (Chondrichthyes: Odontaspidae) from the south-west Atlantic identified using DNA bar coding. Mar. Biodivers. Rec. 4: e75.

Santos HRS and Carvalho MR (2004). Description of a new species of whiptailed stingray from the Southwestern Atlantic Ocean (Chondrichthyes, Myliobatiformes, Dasyatidae). Bol. Mus. Nac. N. S. Zool. 516: 1-24.

Santos HRS, Gomes UL and Charvet-Almeida P (2004). A new species of whiptail stingray of the genus Dasyatis Rafinesque, 1810 from the Southwestern Atlantic Ocean (Chondrichthyes: Myliobatiformes: Dasyatidae). Zootaxa 492: 1-12.

Silva GB, Basílio TH and Nascimento FCP (2007). Distribuição de comprimento das raias Dasyatis guttata e Dasyatis americana no litoral do Estado do Ceará, em função do aparelho-de-pesca. Arq. Ciên. Mar 40: 38-42.

Simpfendorfer CA and Kyne PM (2009). Limited potential to recover from overfishing raises concerns for deep-sea sharks, rays and chimaeras. Environ. Conserv. 36: 97-103.

Swofford DL (2000). PAUP* - Phylogenetic Analysis Using Parsimony (*and Other Methods). Version 4. Sinauer Associates, Sunderland.

Toffoli D, Hrbek T, Araújo MLG, Almeida MP, et al. (2008). A test of the utility of DNA barcoding in the radiation of the freshwater stingray genus Potamotrygon (Potamotrygonidae, Myliobatiformes). Genet. Mol. Biol. 31: 324-336.

Vaz LAL, Carreiro CRP, Goulart-Filho LR and Furtado-Neto MAA (2006). Relações filogenéticas em raias (Dasyatis, Elasmobranchii) do Estado do Ceará, Brasil. Arq. Ciên. Mar 39: 86-88.

Yazbeck GM, Brandão RL, Cunha HM and Paglia AP (2011). Detection of two morphologically cryptic species from the cursor complex (Akodon spp; Rodentia, Cricetidae) through the use of RAPD markers. Genet. Mol. Res. 10: 2881-2892. 